\title{
Meio semi-seletivo para isolamento de Xanthomonas campestris pv. viticola
}

\author{
Semi-selective medium for isolation of Xanthomonas campestris pv. Viticola
}

\author{
Ana Rosa Peixoto ${ }^{1}$ Rosa de Lima Ramos Mariano ${ }^{2}$ \\ Ivanise Oliveira Viana ${ }^{2}$
}

\begin{abstract}
O cancro bacteriano causado por Xanthomonas campestris $p v$. viticola é a fitobacteriose mais importante da videira no Submédio São Francisco. O isolamento de $\boldsymbol{X}$. campestris pv. viticola de tecidos vegetais infectados é dificultado pela presença de contaminantes bacterianos, entre os quais Microbacterium barkeri. Objetivando-se a formulação de meio de cultura semi-seletivo, 22 isolados de $\boldsymbol{X}$. campestris pv. viticola foram testados com relação a 30 antibióticos. O meio semiseletivo NYDAM (extrato de carne 3, peptona 5, glicose 10 , extrato de levedura 5, ágar 18 e ampicilina 0,1 em $\mathrm{g} \mathrm{L}^{-1}$ ) inibiu M. barkeri e bactérias fitopatogênicas podendo ser utilizado para isolar $\boldsymbol{X}$. campestris $p v$. viticola de hospedeiros com infecção natural em campo.
\end{abstract}

Palavras-chave: cancro da videira, Vitis sp., antibióticos.

\section{ABSTRACT}

Bacterial canker caused by Xanthomonas campestris $p v$. viticola is the most important bacterial disease of grapevine in Submédio São Francisco. The isolation of $\boldsymbol{X}$. campestris $p v$. viticola of infected plant tissues is impaired by the presence of bacterial contaminants including Microbacterium barkeri. Aiming to formulate a semi-selective medium $22 \boldsymbol{X}$. campestris $p v$. viticola isolates were tested in relation to 30 antibiotics. The semi-selective NYDAM medium (meat extract 3 , peptone 5 , glucose 10 , yeast extract 5 , agar 18 and ampicilin 0.1 in $\mathrm{gL}^{-1}$ ) inhibited $\mathbf{M}$. barkeri and plant pathogenic bacteria allowing $\boldsymbol{X}$. campestris $p v$. viticola isolation from hosts naturally infected in the field.

Key words: bacterial canker of grapevine, Vitis sp., antibiotics.
No início de 1998, foi detectado, pela primeira vez no Brasil, o cancro bacteriano da videira em parreirais do Submédio São Francisco, onde a doença vem causando prejuízos em cultivares suscetíveis (MALAVOLTA et al., 1999). O agente causal da doença é a bactéria Xanthomonas campestris pv. viticola (Nayudu) Dye, cujo isolamento a partir de órgãos vegetais infectados é muitas vezes dificultado pela presença de bactérias saprófitas, destacando-se um contaminante de cor inicialmente branca e posteriormente amarela, com rápido crescimento, que dificulta o crescimento e reconhecimento de $\boldsymbol{X}$. campestris $p v$. viticola em meios de cultura de rotina, identificado como Microbacterium barkeri.

Meios semi-seletivos são valiosos para o isolamento de bactérias fitopatogênicas de tecidos de plantas e solo e alguns podem ser tão sensíveis quanto a reação da polimerase em cadeia (PCR) (WANG et al., 1999) ou mais sensíveis que técnicas imunológicas (ALVAREZ \& LOU, 1985; WANG et al., 1999), sendo fáceis de usar e menos dispendiosos (TOUSSAINT et al., 2001). Porém, um meio que restringe o surgimento de colônias de microrganismos saprofíticos, geralmente apresenta altos níveis de repressão do patógeno alvo (MOURA \& ROMEIRO, 1998), ou seja, baixa eficiência (WYDRA et al., 2004).

'Departamento de Tecnologia e Ciências Sociais, Universidade do Estado da Bahia (UNEB), Av Edgard Chastnet, s/n, 48900-000, Juazeiro, BA, Brasil.

${ }^{2}$ Departamento de Agronomia, Universidade Federal Rural de Pernambuco (UFRPE), 52171-030, Recife, PE, Brasil. E-mail: rmariano@truenet.com.br. Autor para correspondência (R.L.R. Mariano). 
O objetivo deste trabalho foi formular um meio semi-seletivo para isolamento de $X$. campestris $p v$. viticola a partir de órgãos vegetais infectados.

Vinte e dois isolados de $\boldsymbol{X}$. campestris $p v$. viticola, obtidos de videiras com sintomas típicos do cancro bacteriano ou de plantas invasoras com sintomas similares, coletados em parreirais comerciais (Tabela 1), foram multiplicados e mantidos em meio NYDA (extrato de carne 3, peptona 5, glicose 10, extrato de levedura 5, ágar $18 \mathrm{~g} \mathrm{~L}^{-1}$ de água destilada). A partir de cultivo com 48 horas em NYDA, as suspensões dos isolados foram feitas em água destilada esterilizada (ADE) e aferidas em fotocolorímetro Analyser $500 \mathrm{M}$, de acordo com equação previamente determinada, onde

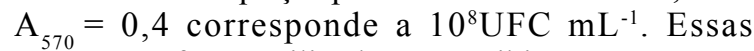
suspensões foram utilizadas nos antibiogramas e testes de eficiência.

Os antibiogramas qualitativos foram realizados em placas de Petri contendo NYDA solidificado, sobre o qual $100 \mu \mathrm{L}$ de suspensão bacteriana foram espalhados. Após secagem da suspensão, quatro discos de antibióticos distintos (Tabela 2) foram depositados por placa, com quatro repetições. A incubação foi realizada a $29^{\circ} \mathrm{C}$, durante 48 horas, quando se verificou a ocorrência ou não de halos de inibição.
No teste de supressividade, foram utilizadas culturas puras das espécies: M. barkeri, Acidovorax avenae subsp. citrulli, Agrobacterium tumefaciens (biovar 1 e biovar 3), Pectobacterium carotovorum subsp. carotovorum, Pseudomonas cichorri, $P$. syringae pv. tomato, Ralstonia solanacearum e Xanthomonas campestris pv. campestris. Cada isolado foi semeado, pelo método de estrias, em placas contendo meio semi-seletivo e NYDA (controle), com quatro repetições. As placas foram incubadas a $29^{\circ} \mathrm{C}$, por 48 horas, quando se verificou o crescimento ou não das culturas.

No teste de eficácia, foram utilizados os isolados Xcv1, 1385-98, UnB1190 e UnB 1216. Alíquotas de $100 \mu \mathrm{L}$ de suspensões bacterianas com $10^{3} \mathrm{UFC} \mathrm{mL}^{-1}$ foram plaqueadas em meio semi-seletivo e NYDA, incubadas por 48 horas, a $29^{\circ} \mathrm{C}$, quando foi feita a contagem de colônias. A eficácia foi determinada pela fórmula $\mathrm{E}(\%)=[(\mathrm{UFC}$ em meio semi-seletivo $) /(\mathrm{UFC}$ em NYDA)] x 100 (WYDRA et al., 2004).

Dos antibióticos testados, amoxicilina $(10 \mu \mathrm{g})$, ampicilina $(10 \mu \mathrm{g})$, cefaclor $(30 \mu \mathrm{g})$, clindamicina $(2 \mu \mathrm{g})$, optoquina $(5 \mu \mathrm{g})$, oxacilina $(1 \mu \mathrm{g})$, nitrofurantoína $(300 \mu \mathrm{g})$ e trimetropina $(5 \mu \mathrm{g})$ apresentaram baixa eficácia (0 a 10\%) contra os isolados de $\boldsymbol{X}$. campestris $p v$.

Tabela 1 - Identificação, hospedeiros, origem e procedência dos isolados de Xanthomonas campestris pv. viticola avaliados para sensibilidade a antibióticos.

\begin{tabular}{llll}
\hline Identificação do isolado & Hospedeiro & Origem & Procedência \\
\hline UnB 1216 & Videira cv. Red Globe & Petrolina-PE & UnB $^{1}$ \\
UnB 1190 & Videira cv. Red Globe & Petrolina-PE & UnB \\
UnB 1223 & Videira cv. Red Globe & Curaçá-BA & UnB \\
UnB 1224 & Videira cv. Red Globe & Curaçá-BA & UnB \\
Xcv1 & Videira cv. Red Globe & Juazeiro-BA & UFRPE \\
Xcv2 & Fedegoso (Senna obtusifolia) & Petrolina-PE & UFRPE \\
Xcv3 & Alecrim (Alternanthera tenella) & Petrolina-PE & UFRPE \\
Xcv4 & Videira cv. Thompson & Petrolina-PE & UFRPE \\
Xcv5 & Videira cv. Superior & Petrolina-PE & UFRPE \\
Xcv6 & Videira cv. Superior & Petrolina-PE & UFRPE \\
Xcv7 & Videira cv. Catalunha & Juazeiro-BA & UFRPE \\
Xcv8 & Videira cv. Catalunha & Juazeiro-BA & UFRPE \\
Xcv9 & Videira cv. Catalunha & Petrolina-PE & UFRPE \\
1370 & Videira cv. Red Globe & Petrolina-PE & Instituto Biológico \\
1376 & Videira cv. Red Globe & Petrolina-PE & Instituto Biológico \\
1377 & Videira cv. Red Globe & Petrolina-PE & Instituto Biológico \\
1385 & Videira cv. Itália & Terezina-PI & Instituto Biológico \\
1386 & Videira cv. Ribiê & Terezina-PI & Instituto Biológico \\
1456 & Videira cv. Red Globe & Santa Maria da Boa Vista-PE & Instituto Biológico \\
1502 & Videira cv. Red Globe & Petrolina-PE & Instituto Biológico \\
1505 & Videira cv. Red Globe & Petrolina-PE & Instituto Biológico \\
1506 & Videira cv. Red Globe & Petrolina-PE & Instituto Biológico \\
\hline
\end{tabular}

\footnotetext{
${ }^{1}$ Universidade de Brasília.

${ }^{2}$ Universidade Federal Rural de Pernambuco.
} 
viticola estudados (Tabela 2). Portanto, esses antibióticos foram adicionados separadamente ao meio NYDA, fazendo-se os testes de crescimento de $\boldsymbol{X}$. campestris $p v$. viticola e do saprófita $M$. barkeri. O único antibiótico que inibiu esta última bactéria foi a ampicilina, quando adicionada ao NYDA na concentração de $100 \mathrm{ppm}$.

A eficácia do meio semi-seletivo variou de 10,8 (isolado Xcv1) a 29,4\% (isolado 1385-98), concordando com TOUSSAINT et al. (2001), que relataram índices de 5,7 a 30,6\% para $X$. campestris pv. vitians em meio MMG. Por outro lado, 45,6 a 188,6\% de eficácia foram obtidas no meio CCM para $\boldsymbol{X}$. axonopodis pv. vignicola (WYDRA et al., 2004) e 65 a $100 \%$ para Pectobacterium carotovorum e Pectobacterium atrosepticum (CUPPELS \& KELMAN, 1974).
O meio semi-seletivo foi supressivo apenas aos isolados de A. avenae subsp. citrulli, de $\boldsymbol{P}$. carotovorum subsp. carotovorum $e$ de Microbacterium barkeri, os quais tiveram o crescimento totalmente inibido. Segundo MOURA \& ROMEIRO (1993), meios semi-seletivos ou seletivos desenvolvidos para outras espécies de bactérias fitopatogênicas podem apresentar alta supressividade. O meio semi-seletivo NYDAM (NYDA + ampicilina) (extrato de carne $3 \mathrm{~g}$, peptona $5 \mathrm{~g}$, glicose $10 \mathrm{~g}$, extrato de levedura $5 \mathrm{~g}$, ágar $18 \mathrm{~g}$, ampicilina $100 \mathrm{mg}$ $\mathrm{L}^{-1}$ de água destilada) desenvolvido neste trabalho permitiu o isolamento de $\boldsymbol{X}$. campestris $p v$. viticola sem a presença de saprófitas, a partir de diversos tecidos vegetais infectados, facilitando a identificação do patógeno. NYDAM é um meio de preparo fácil e

Tabela 2 - Sensibilidade de isolados de Xanthomonas campestris pv. viticola a diferentes antibióticos.

\begin{tabular}{|c|c|c|}
\hline Antibióticos & Concentração & $\%$ de isolados sensíveis ${ }^{1}$ \\
\hline Ácido nalidíxico & $30 \mu \mathrm{g}$ & 100 \\
\hline Ácido Pipemidico & $20 \mathrm{cg}$ & 90 \\
\hline Amicacina & $30 \mu \mathrm{g}$ & 80 \\
\hline Amoxicilina/Ácido clavulânico & $10 \mu \mathrm{g}$ & 90 \\
\hline Amoxicilina $^{2}$ & $30 \mu \mathrm{g}$ & 0 \\
\hline Ampicilina + Sulbactam & $10 \mu \mathrm{g}$ & 55 \\
\hline Ampicilina $^{2}$ & $10 \mu \mathrm{g}$ & 10 \\
\hline Aztreoram & $30 \mu \mathrm{g}$ & 70 \\
\hline Cefaclor $^{2}$ & $30 \mu \mathrm{g}$ & 0 \\
\hline Cefotaxima & $30 \mu \mathrm{g}$ & 100 \\
\hline Cefoxetina & $30 \mu \mathrm{g}$ & 55 \\
\hline Ceftazidima & $30 \mu \mathrm{g}$ & 100 \\
\hline Ceftriaxona & $30 \mu \mathrm{g}$ & 90 \\
\hline Ciprofloxacin & $5 \mu \mathrm{g}$ & 100 \\
\hline Clindamicina $^{2}$ & $2 \mu \mathrm{g}$ & 0 \\
\hline Cloranfenicol & $30 \mu \mathrm{g}$ & 100 \\
\hline Eritromicina & $15 \mu \mathrm{g}$ & 100 \\
\hline Estreptomicina & $10 \mu \mathrm{g}$ & 100 \\
\hline Imipenen & $10 \mu \mathrm{g}$ & 100 \\
\hline Neomicina & $30 \mu \mathrm{g}$ & 90 \\
\hline Netilmicina & $30 \mu \mathrm{g}$ & 100 \\
\hline Nitrofurantoina $^{2}$ & $300 \mu \mathrm{g}$ & 0 \\
\hline Norfloxacin & $10 \mu \mathrm{g}$ & 100 \\
\hline Optoquina $^{2}$ & $5 \mu \mathrm{g}$ & 0 \\
\hline Oxacilina $^{2}$ & $1 \mu \mathrm{g}$ & 0 \\
\hline Sulfazotrin & $25 \mu \mathrm{g}$ & 100 \\
\hline Sulfonamida & $300 \mu \mathrm{g}$ & 80 \\
\hline Tetraciclina & $30 \mu \mathrm{g}$ & 100 \\
\hline Ticarcilina/Ácido Clavulânico & $85 \mu \mathrm{g}$ & 100 \\
\hline Trimetropina $^{2}$ & $5 \mu \mathrm{g}$ & 0 \\
\hline
\end{tabular}

${ }^{1}$ Porcentagem em relação a 22 isolados

${ }^{2}$ Antibiótico com baixa eficácia a isolados de $\boldsymbol{X}$. campestris pv. viticola. 
não requer luz UV ou reagentes para a visualização e contagem de colônias. Nesse meio, bem como em NYDA, as colônias apresentam coloração branca, forma arredondada e bordos lisos, diferindo apenas no diâmetro da colônia (cerca de 1,5mm no meio NYDAM e $2,5 \mathrm{~mm}$ em NYDA) após 48 horas de cultivo a $29^{\circ} \mathrm{C}$. WYDRA et al. (2004) também observaram redução do tamanho das colônias de $\boldsymbol{X}$. axonopodis pv. vignicola de $5 \mathrm{~mm}$ para $1,5 \mathrm{~mm}$ quando usaram o meio semi-seletivo CCM. Para identificação dos isolados obtidos no meio NYDAM, recomenda-se a inclusão de isolados de referência de $\boldsymbol{X}$. campestris $p v$. viticola e a realização de testes de patogenicidade.

\section{AGRADECIMENTOS}

À Fundação de Amparo à Pesquisa do Estado da Bahia (FAPESB), pelo apoio financeiro; à Coordenação de Aperfeiçoamento de Pessoal de Nível Superior (CAPES) e ao Conselho Nacional de Desenvolvimento Científico e Tecnológico (CNPq), pelas bolsas de Doutorado, Produtividade em Pesquisa e Apoio Técnico concedidas.

\section{REFERÊNCIAS}

ALVAREZ, A.M.; LOU, K. Rapid identification of Xanthomonas campestris pv. campestris by ELISA. Plant Disease, Saint Paul, v.69, n.12, p.1082-1086, 1985.
CUPPELS, D.; KELMAN, A. Evaluation of selective media for isolation of soft-rot bacteria from soil and plant tissue. Phytopathology, Saint Paul, v.64, n.4, p.468-475, 1974.

MALAVOLTA JR., V.A. et al. Ocorrência de Xanthomonas campestris pv. viticola em videira no Brasil. Summa Phytopathologica, Jaboticabal, v.25, n.3, p.26-27, 1999.

MOURA, A.B.; ROMEIRO, R.S. Desenvolvimento de um meio seletivo para Pseudomonas syringae pv. lachrymans. Revista Brasileira de Sementes, Brasília, v.15, n.1, p.209-214, 1993.

MOURA, A.B.; ROMEIRO, R.S. Meio seletivo para Ralstonia solanacearum baseado em resistência múltipla natural a antibióticos. Fitopatologia Brasileira, Brasília, v.23, n.4, p.466-470, 1998.

TOUSSAINT, V. et al. A new semi-selective medium for Xanthomonas campestris pv. vitians, the causal agent of bacterial leaf spot of lettuce. Plant Disease, Saint Paul, v.85, n.2, p.131-136, 2001.

WANG, Z. K. et al. Comparison of PCR, BIO-PCR, DIA, ELISA and isolation on semiselective medium for detection of Xanthomonas albilineans, the causal agent of leaf scald of sugarcane. Plant Pathology, Oxford, v.48, n.2, p.245-252, 1999.

WYDRA, K. et al. A diagnostic medium for the semi-selective isolation and enumeration of Xanthomonas axonopodis pv. vignicola. European Journal of Plant Pathology, Dordrecht, v.110, n.10, p.991-1001, 2004. 